\title{
KNOWLEDGE MISALLOCATION AND GROWTH
}

\author{
Xavier Raurich, Fernando Sánchez-Losada, and Montserrat \\ Vilalta-Bufí \\ Universitat de Barcelona \\ and \\ Centre de Recerca en Economia del Benestar (CREB)
}

\begin{abstract}
We develop a growth model where knowledge is embodied in individuals and diffused across sectors through labor mobility. The existence of labor mobility costs constrains mobility and thus generates labor misallocation. Different levels of labor misallocation imply different levels of exploitation of available knowledge and therefore different total factor productivity across countries. We derive a positive relationship between growth and labor mobility, which is consistent with the empirical evidence, by assuming aggregate constant returns to capital. We also analyze the short- and long-run effects of labor mobility costs in the case of decreasing returns to capital. It turns out that changes in mobility costs have larger economic effects when different types of workers have small rather than large complementarities. Finally, we show that different labor income taxes or labor market tightness imply different rates of labor mobility and therefore can explain differences in Gross Domestic Product across countries.
\end{abstract}

Keywords: Economic Growth, Labor Mobility, Knowledge Misallocation

\section{INTRODUCTION}

The empirical growth literature has established that cross-country differences in income per capita cannot be accounted for only by differences in the accumulation of production factors [see McGrattan and Schmitz (1999) and Parente and Prescott (2004)]. Several authors argue that income per capita disparities are mainly explained by differences in total factor productivity (TFP), which are often considered to be the result of differences in the misallocation of inputs [see Klenow and Rodriguez-Clare (1997); Prescott (1998); and Hall and Jones (1999)]. Hsieh and Klenow (2009) corroborate the importance of input misallocation in explaining TFP. They find that reducing labor and capital misallocation in China and India to the U.S. level would increase their TFP by $30 \%$ to $50 \%$ in China and by $40 \%$ to $60 \%$ in India. ${ }^{1}$ The literature has mainly centered on the effects of the joint

\footnotetext{
We acknowledge the comments of Petros Milionis and two anonymous referees. Financial support from the Spanish Ministry of Education through Grant ECO2012-34046 and from the Government of Catalonia through the Barcelona GSE Research Network and Grant 2009SGR1051 is gratefully acknowledged. Address correspondence to: Xavier Raurich, Universitat de Barcelona, Departament de Teoria Econòmica, Facultat d'Economia i Empresa, Avinguda Diagonal 696, 08034 Barcelona, Spain; e-mail: xavier.raurich@ub.edu.
} 
misallocation of inputs on industry dynamics [see Lagos (2006); Restuccia and Rogerson (2008); Hsieh and Klenow (2009, 2010); Poschke (2009); Barseghyan and DiCecio (2011); or Moscoso Boedo and Mukoyama (2012), among many others). The existence of firm entry costs, for instance, lowers aggregate TFP by keeping low-productivity firms in the market. Instead, Banerjee and Moll (2010) and Fernald and Neiman (2011) focus on the effects of the misallocation of capital. In this paper, we contribute to the literature on input misallocation by developing a growth model where knowledge is embodied in individuals and diffused across sectors through labor mobility. ${ }^{2}$ The existence of labor mobility costs constrains mobility and, thus, generates labor misallocation. Thus, different levels of labor misallocation imply different levels of exploitation of available knowledge and, therefore, different TFP across countries.

In the labor economics literature, worker reallocation occurs mainly for two reasons. On one hand, frictions in the labor market create mismatches. This gives incentives to workers to change jobs in order to improve their matches and, consequently, their wages. Therefore, labor mobility is associated with higher productivity in these models [see Jovanovic and Moffit (1990)]. On the other hand, shifts in sectoral labor demand may force individuals to change sectors, which usually involves a loss of sector-specific human capital, and therefore, a potential productivity loss [see Moscarini (2001)]. Shifts in labor demand might be due to preference shocks, business cycle shocks, or technology shocks [see Rogerson (1987) and Dixit and Rob (1994)]. In contrast, in our model, worker reallocation is explained by the complementarity between different types of workers and the dynamics of sector-specific knowledge, which is based on a continuous process of sector-specific learning. These two elements generate worker reallocation even in the absence of frictions and shifts in the sectoral labor demand.

We assume that workers are heterogeneous and not perfect substitutes. ${ }^{3}$ Worker heterogeneity is a consequence of sector-specific learning-by-doing. As mentioned previously, knowledge is diffused across sectors through labor mobility, which is constrained by labor mobility costs. We assume that these costs arise only when firms hire workers from a different sector. ${ }^{4}$ These costs may represent training costs of hiring workers from other sectors, productivity loss when knowledge is sector-specific, higher hiring or search costs of hiring in a different sector, reallocation expenses, or time-consuming labor mobility. More generally, they could embody institutional factors such as labor market regulations and the existence of unions. Obviously, these mobility costs directly affect firms' hiring decisions. Thus, differences in labor mobility costs imply different levels of exploitation of available knowledge and, therefore, different productivity growth across countries. The purpose of this paper is to study the effects of mobility costs on Gross Domestic Product (GDP).

Table 1 reports a measure of labor mobility, GDP per capita level, and GDP per capita growth for nine ${ }^{5}$ European countries and the United States in the period 1994-2008. ${ }^{6}$ We can distinguish between three groups of countries according to their labor mobility level. At one end, Portugal, Spain, Belgium, France, and Italy have a very immobile labor force, with less than one out of ten employees 
TABLE 1. Labor mobility, GDP per capita in 1994, and GDP growth between 1994 and 2008

\begin{tabular}{lccc}
\hline Country & Labor mobility & GDP per capita 1994 & GDP per capita growth (\%) \\
\hline Italy & 6.04 & 25341.52 & 1.11 \\
France & 6.95 & 26068.19 & 1.41 \\
Belgium & 7.3 & 27157.84 & 1.93 \\
Spain & 7.99 & 20875.01 & 2.25 \\
Portugal & 9.41 & 16065.06 & 1.63 \\
Germany & 11.48 & 28093.09 & 1.40 \\
Netherlands & 13.9 & 28695.34 & 2.12 \\
US & 17.92 & 33090.7 & 1.72 \\
Denmark & 25 & 28071.82 & 1.64 \\
UK & 33.16 & 24082.04 & 2.53 \\
Average & 13.92 & 25754.06 & 1.77 \\
\hline
\end{tabular}

Sources: Data on labor mobility from Jolivet et al. (2006) [(\% of job-to-job mobility in a 3 year spell/ \% of nonmobile workers in a 3-year spell $) \times 100$ ] and on GDP per capita and GDP growth from Penn World Table 7.1 [Heston et al. (2012)].

changing jobs in a three-year spell. At the other end, the United Kingdom and Denmark are highly mobile, with at least one out of five employees changing jobs in a three-year spell. In between, there are the United States, the Netherlands, and Germany. The correlation between labor mobility and GDP growth is 0.52 and the coefficient of labor mobility on GDP growth controlling for initial GDP level is positive and significant (adjusted $R^{2}$ is close to $15 \%$ ).

We build on the seminal paper of Arrow (1962), where learning-by-doing is the main determinant of firms' productivity growth. Arrow assumes that knowledge learned in a firm gets freely and instantly spread to the whole economy. However, the assumption of instant diffusion and utilization of new knowledge across all sectors seems unrealistic. We assume instead that diffusion of knowledge across sectors is costly and requires channels of transmission. In particular, we assume that firms learn by hiring workers from other sectors (learning-by-hiring). Moreover, we assume that productivity increases with the exchange of knowledge by introducing complementarities among different types of workers. ${ }^{7}$ Hence, hiring decisions (and, thus, worker mobility) affect knowledge exploitation and the TFP.

As in Arrow (1962), the learning in one sector is a function of the investment made last period in that sector. As a result, the productivity (or embodied knowledge) of a worker hired from a particular sector is directly related to the accumulated stock of physical capital in that sector. Hence, we distinguish among types of workers by the sectors in which they have been employed. Moreover, the possibility of learning-by-hiring allows for different degrees of substitution among the different worker types, which we include by defining the labor input as a constant-elasticity-of-substitution (CES) aggregator of the different workers.

We consider two scenarios. In the first scenario, we assume aggregate constant returns to capital so that endogenous growth arises, as in Arrow (1962). The equilibrium does not exhibit transition, and consumption, capital, and GDP grow 
at the same constant rate, whereas labor mobility is constant. We show that higher mobility costs imply both lower labor mobility and lower GDP growth, which explains the empirical evidence reported in Table 1. We illustrate these results numerically, finding that differences in labor mobility costs can explain up to $53 \%$ of differences in growth rates. Therefore, our model suggests that cross-country differences in GDP growth rates can be explained partially by labor misallocation due to differences in labor mobility costs.

Because each sector is identified with a type of knowledge, we also find that the number of sectors affects growth. We distinguish two different effects. On one hand, an increase in the number of sectors directly raises TFP. On the other hand, it reduces the number of workers of each type and, therefore, reduces TFP. The trade-off between these two effects depends on the ease with which one worker can substitute for another and, therefore, is driven by the elasticity of substitution between them. When workers are highly complementary, the negative effect dominates and an increase in the number of sectors reduces the GDP growth rate. The opposite happens when workers are easily substitutable. ${ }^{8}$

In the second scenario, we assume aggregate decreasing returns to capital, implying exogenous growth and nonconstant labor mobility during the transition. In this scenario, not only the standard decreasing returns to capital but also learningby-hiring drives the transition. The equilibrium is unique and converges to a steady state where both labor mobility and GDP remain constant. We show that a permanent reduction in labor mobility costs causes a permanent increase in labor mobility, TFP, and income per capita. The effects are much larger when workers are easily substitutable. In this case, firms more frequently replace workers from their own sector with workers from another sector, so that a reduction in the labor mobility cost causes a greater increase in the long-run level of GDP.

We conclude that labor mobility costs, by causing labor misallocation, explain differences in income per capita across countries. Thus, a crucial issue is to explain the sources of differences in labor mobility costs across countries. ${ }^{9}$ To this end, we further the understanding of mobility costs through the analysis of two wellknown economic issues: labor income taxes and labor search costs. We show that differences in either taxes or search costs can explain differences in labor mobility across countries and, therefore, in their income per capita. In particular, labor income taxes amplify the distortion generated by labor mobility costs and, thus, indirectly affect TFP through labor mobility. As a result, labor income taxes not only reduce employment, as shown in Prescott (2004), but also reduce TFP. ${ }^{10}$ When considering labor search costs, we show that vacancy costs amplify labor mobility costs and, thus, indirectly affect TFP. But, as they are a type of mobility cost, they directly affect TFP even in the absence of other mobility costs. ${ }^{11} \mathrm{We}$ find that countries with high labor market tightness suffer a larger GDP reduction because of an increase in mobility costs than countries with low market tightness.

The paper is organized as follows. In Sections 2 and 3 we describe the model and derive the equilibrium, respectively. In Section 4 we analyze the scenario with constant aggregate returns to capital, which is directly comparable to Arrow (1962). In Section 5 we study the effects of labor mobility on the transitional 
dynamics of an otherwise standard Ramsey-Cass-Koopmans model. We expand the discussion on mobility costs in Section 6, where the role of labor income taxes and search costs is analyzed. Finally, we conclude in Section 7. All the proofs are in the Appendices.

\section{THE MODEL}

Consider a continuous-time economy with a perfectly competitive final goods sector and a continuum of intermediate sectors with a constant measure $S$. The technology in the final goods sector is defined by the following CES production function: ${ }^{12}$

$$
Y=\left(S^{\mu-1} \int_{0}^{S} Y_{i}^{\mu} d i\right)^{\frac{1}{\mu}}
$$

where $Y$ denotes final goods production, $Y_{i}$ is the amount of intermediate goods of sector $i$ used in the production of the final good, and the elasticity of substitution between two intermediate goods is measured by $1 /(1-\mu)$, with $\mu \leq 1$. Note that this production function does not exhibit scale effects.

Any final goods firm solves the following profit maximization problem:

$$
\max _{\left\{Y_{i}\right\}} Y-\int_{0}^{S} p_{i} Y_{i},
$$

subject to (1), where $p_{i}$ is the price of the intermediate good of sector $i$ in units of the final good. From the first-order conditions, we obtain the inverse demand for any intermediate good as

$$
p_{i}=\left(\frac{Y}{Y_{i}}\right)^{1-\mu} S^{\mu-1}
$$

Intermediate goods sectors use labor and physical capital as inputs. Workers are infinitely lived and in each period learn the knowledge of the sector in which they are employed without any cost (learning-by-doing). Firms are interested in the knowledge a worker has learned in the last period. Therefore, we distinguish among types of worker by the sectors in which they have been employed last period. This assumption implies that workers have the same sector-specific knowledge after working one period in the same sector. Following Arrow (1962), knowledge of sector $i$ is related to the stock of capital in that sector. In particular, we assume that the knowledge of sector $i$ coincides with the average per-worker stock of physical capital in that sector, $\bar{k}_{i} .{ }^{13}$ Because learning is embodied in workers, it is not internalized by firms when they make their own investment decisions. ${ }^{14}$ However, the amount of knowledge accumulated by each type of worker is a determinant of the hiring decisions of the firm. In fact, by hiring workers from other sectors, firms learn from the investment decisions made in other sectors. Denote by $\lambda_{i}^{j}$ the number of workers from sector $j$ that are hired in sector $i$. As stated earlier, they have embodied knowledge of sector $j, \bar{k}_{j}$. We call them poached workers. 
Similarly, let $\eta_{i}$ be the number of workers from sector $i$ hired by the same sector $i$, who have knowledge of sector $i, \bar{k}_{i}$. We call them retained workers.

There is a continuum of firms of measure 1 in each sector. We assume that the production function of a firm of sector $i$ is

$$
Y_{i}=\left[\left(\eta_{i} \bar{k}_{i}^{\xi}\right)^{\sigma}+q \int_{0}^{S}\left(\lambda_{i}^{j} \bar{k}_{j}^{\xi \phi}\right)^{\sigma} d j\right]^{\frac{\alpha}{\sigma}} K_{i}^{1-\alpha},
$$

where $K_{i}$ is the stock of physical capital, $\xi \in[0,1]$ measures the return from learning, $1 /(1-\sigma) \geq 0$ is the elasticity of substitution among different types of worker, with $\sigma \leq 1$ and $\sigma \neq 0$, and $\alpha \in(0,1)$ measures the labor income share. The parameter $q \geq 0$ measures the ability of learning-by-hiring from other sectors and $\phi \in(0,1 / \xi]$ measures the differences in the return from learning between poaching and retaining. We also assume that $\phi \leq 1 / \xi$ to have nonincreasing returns to capital at the aggregate level.

The production function (3) can be rewritten as $Y_{i}=\psi_{i} N_{i}^{\alpha} K_{i}^{1-\alpha}$, where $N_{i}$ is the number of workers and the variable

$$
\psi_{i}=\left[\left(\frac{\eta_{i}}{N_{i}} \bar{k}_{i}^{\xi}\right)^{\sigma}+q \int_{0}^{S}\left(\frac{\lambda_{i}^{j}}{N_{i}} \bar{k}_{j}^{\xi \phi}\right)^{\sigma} d j\right]^{\frac{\alpha}{\sigma}}
$$

is the standard measure of TFP. When $q=0$, external knowledge is not productive, so that there is no labor mobility $\left(\eta_{i}=N_{i}\right.$ and $\left.\lambda_{i}^{j}=0\right)$ and $\psi_{i}=\bar{k}_{i}^{\alpha \xi}$. In this case, $\psi_{i}$ increases with the capital stock as in the seminal papers of the endogenous growth literature [see Arrow (1962); Romer (1986); Barro (1990); and Rebelo (1991), among many others]. In contrast, when $q>0$, the TFP depends on the hiring decisions and, specifically, on the ability both to retain workers and to hire workers from other sectors. This introduces a relevant difference: firms change their TFP when they choose between retaining and poaching.

Firms maximize profits in a perfectly competitive market; i.e.,

$$
\max _{\left\{\eta_{i}, \lambda_{i}^{j}, K_{i}\right\}} p_{i} Y_{i}-(r+\delta) K_{i}-\int_{0}^{S} w_{i}^{j} \lambda_{i}^{j} d j-w_{i}^{i} \eta_{i},
$$

subject to (3) and (4), where $r$ is the rental cost of capital, $\delta \in(0,1)$ is the depreciation rate, $w_{i}^{j}$ is the salary paid in sector $i$ to workers poached from sector $j$, and $w_{i}^{i}$ is the salary paid in sector $i$ to the retained workers. ${ }^{15}$ The first-order conditions with respect to $\eta_{i}, \lambda_{i}^{j}$, and $K_{i}$ are

$$
\begin{gathered}
\alpha p_{i} \psi_{i}^{\frac{\alpha-\sigma}{\alpha}} N_{i}^{\alpha-\sigma} \eta_{i}^{\sigma-1} \bar{k}_{i}^{\xi \sigma} K_{i}^{1-\alpha} \leq w_{i}^{i}, \\
\alpha p_{i} \psi_{i}^{\frac{\alpha-\sigma}{\alpha}} N_{i}^{\alpha-\sigma} q\left(\lambda_{i}^{j}\right)^{\sigma-1} \bar{k}_{j}^{\xi \phi \sigma} K_{i}^{1-\alpha} \leq w_{i}^{j}, \\
(1-\alpha) p_{i} \psi_{i} N_{i}^{\alpha} K_{i}^{-\alpha}=r+\delta
\end{gathered}
$$

where (5) and (6) hold with equality when $\eta_{i}>0$ and $\lambda_{i}^{j}>0$, respectively. 
We assume that switching among sectors is costly and that these mobility costs are proportional to the wage. ${ }^{16}$ Because any poached worker has to pay these mobility costs, in order to hire an external worker, the firm has to pay her at least the same wage as in the worker's initial firm plus mobility costs, i.e.,

$$
w_{i}^{j} \geq m w_{j}^{j}
$$

where $m-1>0$ measures mobility costs as a percentage of the wage. These labor mobility costs introduce an inefficiency into the labor market: the marginal productivity of a worker does not equalize across sectors, thereby giving rise to labor misallocation.

Perfect competition implies that (8) holds with equality, i.e., $w_{i}^{j}=m w_{j}^{j}$ for all $j \neq i$. In fact, the labor income net of mobility costs obtained by a poached worker is $w_{j}^{j}$. This implies that the net labor income $w_{j}^{j}$ does not depend on the sector in which a worker is employed, but on the sector in which she was employed during the last period, as this determines the worker's specific knowledge.

The economy is populated by a large family of $N$ members. Population size is constant and each member supplies inelastically one unit of labor. Thus, the family labor income net of mobility cost is $W=\int_{0}^{S} w_{i}^{i} \eta_{i} d i+\int_{0}^{S} \int_{0}^{S} w_{j}^{j} \lambda_{i}^{j} d i d j$. This labor income can either be consumed or be invested. Then, the budget constraint of the family is

$$
C+\dot{A}=r A+W
$$

where $C$ is aggregate consumption and $A$ are financial assets. Each member's utility function is

$$
u(c)=\frac{c^{1-\theta}-1}{1-\theta}
$$

where $c=C / N$ is individual consumption and $1 / \theta>0$ measures the intertemporal elasticity of substitution. The family maximizes $\int_{0}^{\infty} N e^{-\rho t} u(c) d t$ subject to (9) and (10), where $\rho$ is the subjective discount factor. From this maximization problem, we obtain that the consumption growth rate satisfies

$$
\frac{\dot{c}}{c}=\frac{r-\rho}{\theta}
$$

The capital market clearing condition is $A=K$, where $K=\int_{0}^{S} K_{i} d i$ is the aggregate capital stock. The final goods market clearing condition implies that

$$
Y=C+\dot{K}+\delta K+M
$$

where $Y$ is GDP and $M$ measures the aggregate mobility costs in units of final goods. In other words, total production is devoted to consumption, investment, 
and mobility costs. ${ }^{17}$ These mobility costs are defined as

$$
M=\int_{0}^{S} \int_{0}^{S}(m-1) w_{j}^{j} \lambda_{i}^{j} d i d j .
$$

Recall that $N_{i}$ denotes total employment in sector $i$. Thus, the labor demand in this sector is

$$
N_{i}=\eta_{i}+\int_{0}^{S} \lambda_{i}^{j} d j,
$$

and the labor market clearing condition implies that

$$
\int_{0}^{S} N_{i} d i=N
$$

Finally, from (14) and (15), we obtain

$$
\int_{0}^{S} \eta_{i} d i+\int_{0}^{S} \int_{0}^{S} \lambda_{i}^{j} d i d j=N .
$$

\section{EQUILIBRIUM}

In this section we characterize the symmetric equilibrium, which is defined as an equilibrium path where all intermediate good sectors produce using the same amount of inputs: $K_{i}=K / S, \eta_{i}=\eta$, and $\lambda_{i}^{j}=\lambda^{j}$ for all $i$. Condition (14) implies that in a symmetric equilibrium $\lambda^{j}=\lambda$ for all $j$ and (15) implies that $N_{i}=N / S$ workers are employed in each sector. ${ }^{18}$ The per capita stock of capital satisfies $k=K / N=S K_{i} / S N_{i}=k_{i}=\bar{k}_{i}$ for all $i$ and, hence, $\psi_{i}=\psi=$ $\left[\left(\frac{S \eta}{N} \bar{k}^{\xi}\right)^{\sigma}+q S\left(\frac{S \lambda}{N} \bar{k}^{\xi \phi}\right)^{\sigma}\right]^{\alpha / \sigma}$. From the production function, we obtain that $Y_{i}=$ $Y_{j}$ for all $i$ and $j$. Then, using equation (1), we obtain that GDP is $Y=S Y_{i}$ and, using equation (2), the price level of the intermediate good is $p_{i}=1$ for all $i$. Finally, equation (5) implies that $w_{i}^{i}=w_{j}^{j}=w$.

We measure labor mobility using the ratio between poached and retained workers, $x=S \lambda / \eta$. Then, in a symmetric equilibrium, the first-order conditions (5), (6), and (7) become

$$
\begin{gathered}
\alpha \psi \frac{\alpha-\sigma}{\alpha} S^{\sigma-1} N^{1-\sigma} \eta^{\sigma-1} k^{1-\alpha+\xi \sigma} \leq w, \\
\alpha \psi{ }^{\frac{\alpha-\sigma}{\alpha}} S^{\sigma-1} N^{1-\sigma} \eta^{\sigma-1} k^{1-\alpha+\xi \sigma \phi} q S^{1-\sigma} x^{\sigma-1} \leq m w, \\
(1-\alpha) \psi k^{-\alpha}=r+\delta
\end{gathered}
$$

where (17) and (18) hold with equality when $\eta>0$ and $\lambda>0$, respectively. Moreover, the labor market clearing condition (16) implies that

$$
\eta=\left(\frac{N}{S}\right)\left(\frac{1}{1+x}\right)
$$


and, from (1), (3), (20), and the definition of $\psi$, GDP per capita, $y=Y / N$, is equal to

$$
y=\left[\frac{\left(1+q S^{1-\sigma} x^{\sigma} k^{\xi(\phi-1) \sigma}\right)^{\frac{1}{\sigma}}}{1+x}\right]^{\alpha} k^{1-\alpha(1-\xi)} .
$$

Finally, combining (12) and (13), and noting that $\dot{k}=\dot{K} / N$, we obtain

$$
\dot{k}=y-c-\delta k-\left(\frac{S}{N}\right)(m-1) w x \eta .
$$

DEFINITION 1. A dynamic equilibrium is a path $\{x, \eta, c, k, w, r, y\}$ that, given the initial stock of capital $k_{0}$, solves the system of differential equations (11) and (22), and satisfies (17)-(21) and the transversality condition $\lim _{t \rightarrow \infty} e^{-\rho t} c^{-\theta} k=0$.

We claim that the equilibrium path is interior when the numbers of retained and poached workers are both positive. In this case, (17) and (18) hold with equality and we obtain the following nontrivial expression for labor mobility:

$$
x=S\left[\left(\frac{q}{m}\right) k^{\xi \sigma(\phi-1)}\right]^{\frac{1}{1-\sigma}} .
$$

The following proposition characterizes the conditions that make the path of the dynamic equilibrium interior.

PROPOSITION 1. When $\sigma<1$, the path of the dynamic equilibrium is interior and labor mobility is measured by (23), and when $\sigma=1$, the path of the dynamic equilibrium is noninterior and there exists a value of the per capita stock of capital, $\widetilde{k}=(m / q)^{1 / \xi(\phi-1)}$, such that

(a) If $k>\underset{\tilde{k}}{\tilde{k}}$ then $\eta=0, \lambda=N / S^{2}$, and $x \rightarrow \infty$.

(b) If $k<\underset{\kappa}{\tilde{k}}$ then $\eta=N / S, \lambda=0$, and $x=0$.

(c) If $k=\widetilde{k}$ then $\eta>0, \lambda>0$, and $x$ is indeterminate.

This proposition shows that the equilibrium is interior when different types of worker are not perfect substitutes. Table 1 reveals that only a positive fraction of workers are mobile, implying that the relevant case is that of an interior equilibrium $(\sigma<1)$. Therefore, hereafter, we allow any degree of substitution between types of worker except for the empirically nonrelevant case of perfect substitution.

When $\phi \neq 1$, there is a differential return from learning between poaching and retaining. As follows from (23), this differential return implies that capital accumulation causes a substitution effect between the two types of worker and, thus, labor mobility changes as capital accumulates. If $\phi<1$, as capital increases, the productivity of poached workers decreases with respect to the productivity of retained workers. This drives two different effects: a substitution effect and a 
production effect. The first effect implies that less productive workers should be replaced by more productive workers, whereas the second effect implies that a larger number of less productive workers should be hired to maintain the level of production. The first effect dominates when workers are highly substitutive $(\sigma>0)$ and the second effect dominates when workers are highly complementary $(\sigma<0)$. As a result, capital accumulation increases (decreases) labor mobility when the elasticity of substitution is lower (higher) than one. Obviously, the same rationale explains that if $\phi>1$ then, as capital accumulates, labor mobility increases when $\sigma>0$ and decreases when $\sigma<0$. Equation (23) also shows that labor mobility is proportional to the number of sectors and decreases with the labor mobility cost.

Using (19), (20), (23), and the definition of $\psi$, the interest rate can be written as

$$
r+\delta=(1-\alpha) h(x) k^{\alpha(\xi-1)},
$$

where

$$
h(x)=\left[\frac{(1+m x)^{\frac{1}{\sigma}}}{1+x}\right]^{\alpha} .
$$

Combining (20), (21), and (23), we obtain

$$
y=h(x) k^{1-\alpha(1-\xi)},
$$

and from (17), (21), (23), and the definition of $\psi$, we have

$$
w=\alpha\left(\frac{1+x}{1+m x}\right) y .
$$

Using (11) and (24), we obtain

$$
\frac{\dot{c}}{c}=\frac{(1-\alpha) h(x) k^{\alpha(\xi-1)}-\delta-\rho}{\theta},
$$

and substituting (26) and (27) into (22) gives

$$
\frac{\dot{k}}{k}=\left[1-\alpha\left(\frac{(m-1) x}{1+x m}\right)\right] h(x) k^{\alpha(\xi-1)}-\frac{c}{k}-\delta .
$$

DEFINITION 2. Assume that $\sigma<1$. Given $k_{0}$, a dynamic interior equilibrium is a path $\{c, k, x, y\}$ that solves the system of differential equations (28) and (29), and satisfies equations (23) and (26) and the transversality condition $\lim _{t \rightarrow \infty} e^{-\rho t} c^{-\theta} k=0$.

As follows from (24), on this interior equilibrium path, dynamics is driven by two different forces: the decreasing returns to capital and the learning-byhiring. The first force arises when $\xi<1$ and the second when labor mobility is not constant, which requires $q>0$ and $\phi \neq 1$. The properties of the dynamic equilibrium will depend heavily on which of these two sources of transition is 
active. In this paper, we will consider two very different scenarios. In Section 4, we assume that $\xi=\phi=1$, which implies that neither of the two forces driving the transition is active. In this case, the equilibrium will exhibit sustained endogenous growth. We use this case to make a direct comparison with the classical endogenous growth models [see Arrow (1962); Romer (1986); Rebelo (1991)]. In Section 5, we assume that $\xi<1$, which implies that the equilibrium exhibits a transition driven at least by the diminishing returns to capital, and growth is exogenous. We use this case to study the effects of labor mobility along the transition. ${ }^{19}$

\section{ENDOGENOUS GROWTH}

In this section we characterize the dynamic equilibrium when $\xi=1$ and $\phi=1$. As follows from Proposition 1 and equation (23), when $\phi=1$, labor mobility is constant and equal to

$$
x^{*}=S\left(\frac{q}{m}\right)^{\frac{1}{1-\sigma}} .
$$

In this case, both the interest rate and the consumption growth rate are also constant. Moreover, from (26), we obtain that the production function simplifies to

$$
y=h\left(x^{*}\right) k,
$$

which is an AK function. TFP is measured by $h\left(x^{*}\right) k^{\alpha}$ and it is endogenous, as it depends on labor mobility $x^{*}$. Finally, as is standard in AK models, the final goods market clearing condition and the transversality condition imply that the equilibrium does not exhibit transition and that capital, consumption, and GDP grow at the same constant rate.

PROPOSITION 2. Assume that $\xi=1, \phi=1$ and $\sigma<1$. The equilibrium does not exhibit transition, and GDP, capital, and consumption grow at the same rate,

$$
g=\frac{(1-\alpha) h\left(x^{*}\right)-\delta-\rho}{\theta} .
$$

It is worth highlighting that if $q=0$ then there is no labor mobility, $h(0)=1$, and $g=[(1-\alpha)-\delta-\rho] / \theta$. Thus, the long-run growth rate coincides with the rate obtained in Arrow's economy. In contrast, if $q>0$, then labor mobility affects the growth rate through the TFP, as stated in the following proposition.

PROPOSITION 3. Assume that $\xi=1, \phi=1, \sigma<1$, and $q>0$. Then

(a) An increase in the mobility cost $m$ reduces the GDP growth rate.

(b) An increase in the number of sectors $S$ increases the GDP growth rate if the elasticity of substitution among worker types is higher than one $(\sigma>0)$ and decreases the GDP growth rate if this elasticity is lower than one $(\sigma<0)$.

An increase in the mobility cost $m$ reduces labor mobility and, thus, both the TFP and the GDP growth rates decrease. Note that when mobility costs are 
zero $(m=1)$, firms are not constrained when hiring and, thus, GDP growth is maximum. ${ }^{20}$

In this model, an increase in the measure of sectors $S$ also affects the GDP growth rate. This effect is well known in the growth literature [see the growth model based on the variety of products in Romer (1990), for example]. However, in these models this effect is positive because it is caused by a scale effect. In contrast, we have assumed that there are no scale effects and, therefore, an increase in $S$ affects growth only because it increases labor mobility. We can identify two different forces. On the one hand, an increase in $S$ raises TFP by increasing the number of types of worker. On the other hand, because population size is constant, it reduces the number of workers of each type and, therefore, reduces TFP. The result of these two forces depends on the ease of worker substitution and, therefore, is driven by the elasticity of substitution. When this elasticity of substitution is higher than one, the positive effect dominates and a larger $S$ increases the GDP growth rate. The opposite happens when the elasticity of substitution is lower than one. In this case, workers are highly complementary and higher growth is achieved if there are fewer types of worker and a larger number of workers of each type.

In what follows we illustrate these results numerically. To this end, we fix the value of the parameters as follows: $\theta=2$ and $\alpha=0.65$, implying that the intertemporal elasticity of substitution (IES) is 0.5 and the labor income share equals $65 \%$, respectively. $\delta=6.47 \%$ and $\rho=0.0176$, implying that the annual interest rate equals $5.2 \%$ and the growth rate is $1.72 \%$, as indicated in Table 1. Finally, we set $m=1.5988, \sigma=-0.1659$, and $S q^{1 /(1-\sigma)}=0.2165$ to jointly determine the following targets: ratio of capital to GDP equals 3 , ratio of consumption to GDP equals 0.7 , and the level of labor mobility equals $18 \%$, which is the value of labor mobility in the United States. ${ }^{21}$ Note that the value of $\sigma$ is negative, implying a value of the elasticity of substitution lower than one. This implies that an increase in the number of sectors reduces the growth rate of the economy, as it reduces the number of workers in each sector. Obviously, this negative result is a consequence of the assumed technology without scale effects. Note also that the calibrated measure of mobility costs (60\% of annual wage) is consistent with the results of Lee and Wolpin (2006), who estimate direct mobility costs for the United States to range between 50\% and 75\% of average annual earnings.

Figure 1 illustrates the effects of changing mobility costs on the GDP growth rate according to our model (solid line), together with the actual data and the linear regression (dashed line). An increase in mobility costs causes a reduction in both labor mobility and GDP growth. This positive relationship between growth and labor mobility is consistent with the empirical evidence. Therefore, our model suggests that cross-country differences in GDP growth rates can be partially explained by differences in labor mobility costs. In our numerical exercise, $m$ takes values between 1 (no mobility costs) and 5.7 (mobility costs are 4.7 times the annual wage), implying in the latter case a mobility rate of $6 \%$, close to the mobility rate in Italy, which is the country with the lowest mobility rate in our 


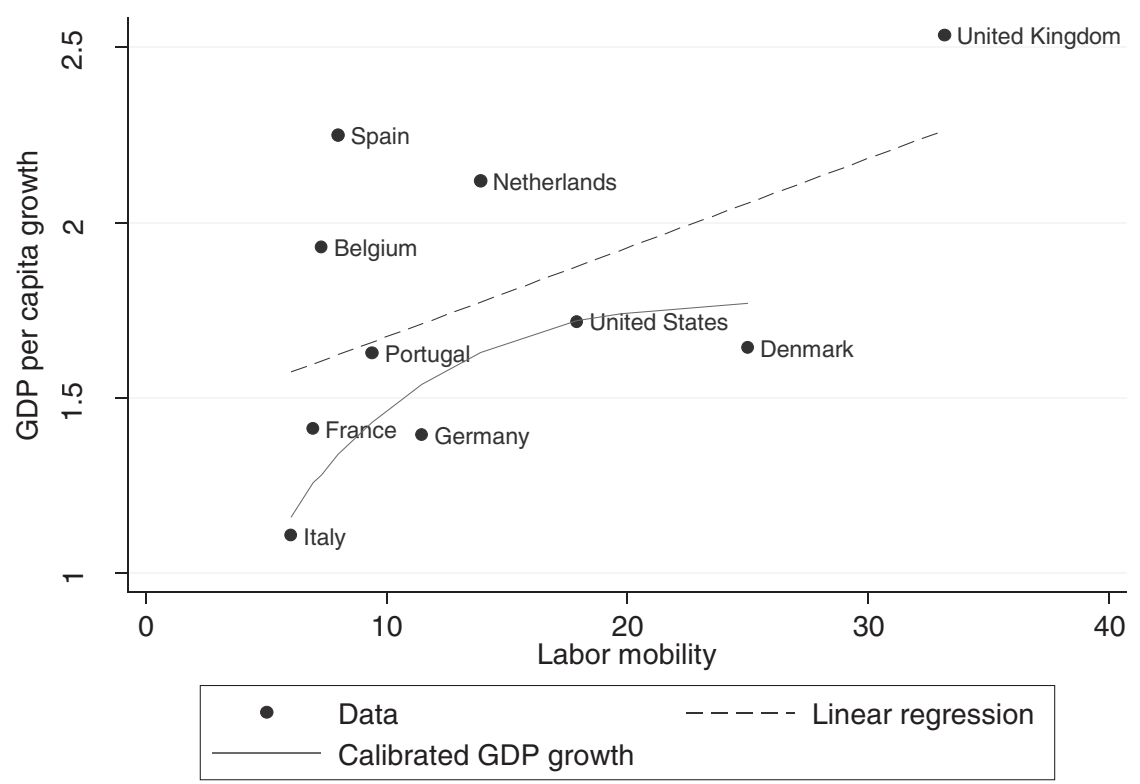

FIGURE 1. Labor mobility and GDP per capita growth. Data on labor mobility from Jolivet et al. (2006) [ $(\%$ of job-to-job mobility in a 3 year spell/\% of nonmobile workers in a 3 -year spell $) \times 100]$ and on GDP per capita growth from Penn World Table 7.1.

sample. This range explains up to $53 \%$ of the differences in GDP growth rates. ${ }^{22}$ Therefore, we conclude that labor mobility costs are a potentially relevant source of cross-country differences in growth rates.

\section{EXOGENOUS GROWTH}

In this section we analyze the equilibrium when $\xi<1$. In this case, the production function exhibits decreasing returns to capital and the economy converges to a steady state where capital and consumption remain constant. The uniqueness of the steady state is guaranteed only when $\phi \leq 1 .{ }^{23}$ Thus, in what follows we assume that this condition is satisfied.

PROPOSITION 4. Assume that $\xi<1, \phi \leq 1$, and $\sigma<1$. Then there is a unique and saddlepath-stable steady state.

We must distinguish between the following two cases. When $\phi=1$, capital accumulation does not change the differential productivity between poached and retained workers and, as a result, labor mobility is constant. In this case, transitional dynamics is driven only by the decreasing returns to capital and, hence, it is identical to the transitional dynamics in the Ramsey-Cass-Koopmans model. In contrast, when $\phi<1$, two forces drive the transition: decreasing returns to capital and nonconstant labor mobility. In this section, we first numerically compare 

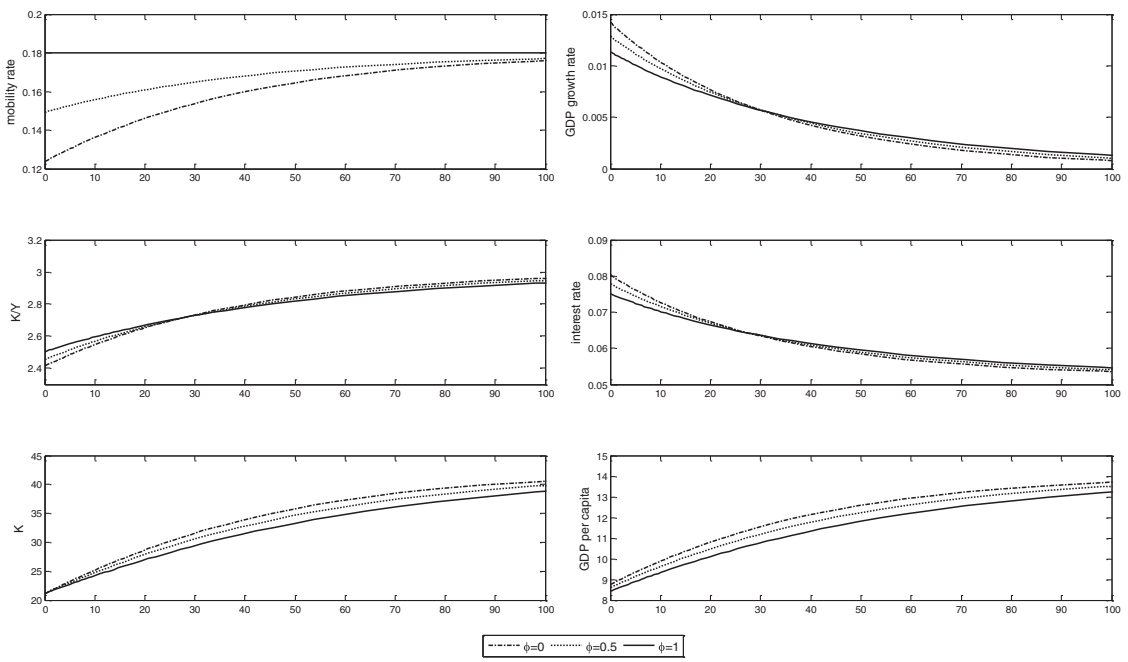

FIGURE 2. Transitional dynamics when the elasticity of substitution is 0.1 and the initial stock of capital is $50 \%$ of its long-run value.

these two different cases to show the effects of labor mobility on the dynamic equilibrium. And, second, we consider the effects of a reduction in labor mobility costs.

We fix the value of the parameters as follows: $\theta=2$ and $\alpha=0.65$, implying an IES of 0.5 and a labor income share of $65 \%$. The annual interest rate equals $5.2 \%$, implying that $\rho=0.052$. And $\delta=6.47 \%$, implying that the ratio of capital to GDP equals 3. We set the value $m=1.4993$, which implies that the ratio of consumption to GDP equals $76 \% .^{24}$ The value of $S q^{1 /(1-\sigma)}$ is set so that in the long run $x=18 \%$, which is the level of labor mobility in the United States. Finally, $\xi=0.6$, implying a speed of convergence equal to $2 \%$ when $\phi=1$. Note that, in contrast to the previous section, the elasticity of substitution among the different types of worker is now a free parameter. In the following we compare the case of workers being complements $(\sigma=-9$ and the elasticity of substitution equals 0.1 ) with the case of workers being substitutes ( $\sigma=0.9$ and the elasticity of substitution equals 10). This comparison allows us to ascertain the importance of this elasticity of substitution.

Figure 2 shows the transitional dynamics when the initial stock of capital is $50 \%$ of its long-run value and the elasticity of substitution among the different types of worker is $0.1(\sigma=-9)$. The continuous, dotted, and dashed lines display the economy when $\phi=1, \phi=0.5$, and $\phi=0$, respectively. As mentioned earlier, when $\phi=1$, the labor mobility rate is constant and, hence, the transitional dynamics is identical to that obtained in the neoclassical growth model without labor mobility, where convergence depends exclusively on the decreasing returns to capital. In the initial periods, the interest rate is high because capital is below its 

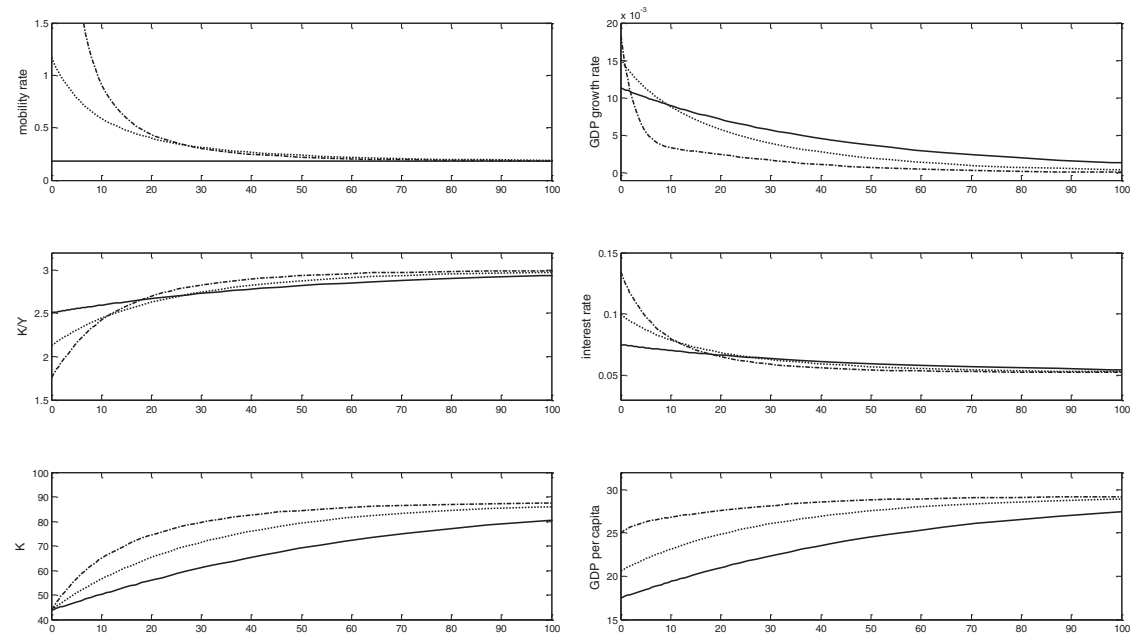

$-\cdots \cdots+\phi \cdots \cdots \cdots=0.5-\phi=1$

FIGURE 3. Transitional dynamics when the elasticity of substitution is 10 and the initial stock of capital is $50 \%$ of its long-run value.

long-run value. High interest rates cause a rapid accumulation of capital, which explains the initially high GDP growth rates. As capital accumulates, the interest rate decreases, which reduces the growth of both capital and GDP. In contrast, when $\phi<1$, labor mobility is not constant and affects the transitional dynamics of the main economic variables, including the GDP growth rate. As capital increases, the relative productivity of poached workers decreases. But, because poached and retained workers are highly complementary $(\sigma<0)$, firms have to increase the number of poached workers to compensate for their lower relative productivity and thus labor mobility increases during the transition. These changes in labor mobility imply a higher interest rate in the initial periods when $\phi<1$. Obviously, this implies a faster capital accumulation. Indeed, the asymptotic speed of convergence is $2.7 \%$ when $\phi=0$ and $2.4 \%$ when $\phi=0.5$. These speeds of convergence are clearly higher than the speed of convergence when $\phi=1$. This faster convergence explains why in the initial periods the GDP growth rate is higher when $\phi<1$ and eventually becomes lower.

Figure 3 shows the transitional dynamics when the initial stock of capital is $50 \%$ of its long-run value and the elasticity of substitution among the different types of worker is $10(\sigma=0.9)$, implying that workers are highly substitutable. The transitional dynamics is very similar to that obtained in Figure 2, and the conclusions from the comparison between the economy with a constant mobility rate and the economy with a nonconstant mobility rate are the same. However, there are two main differences with respect to the transitional dynamics obtained when workers are complementary. First, when poached and retained workers are highly substitutable, firms decrease the number of poached workers during the transition. 

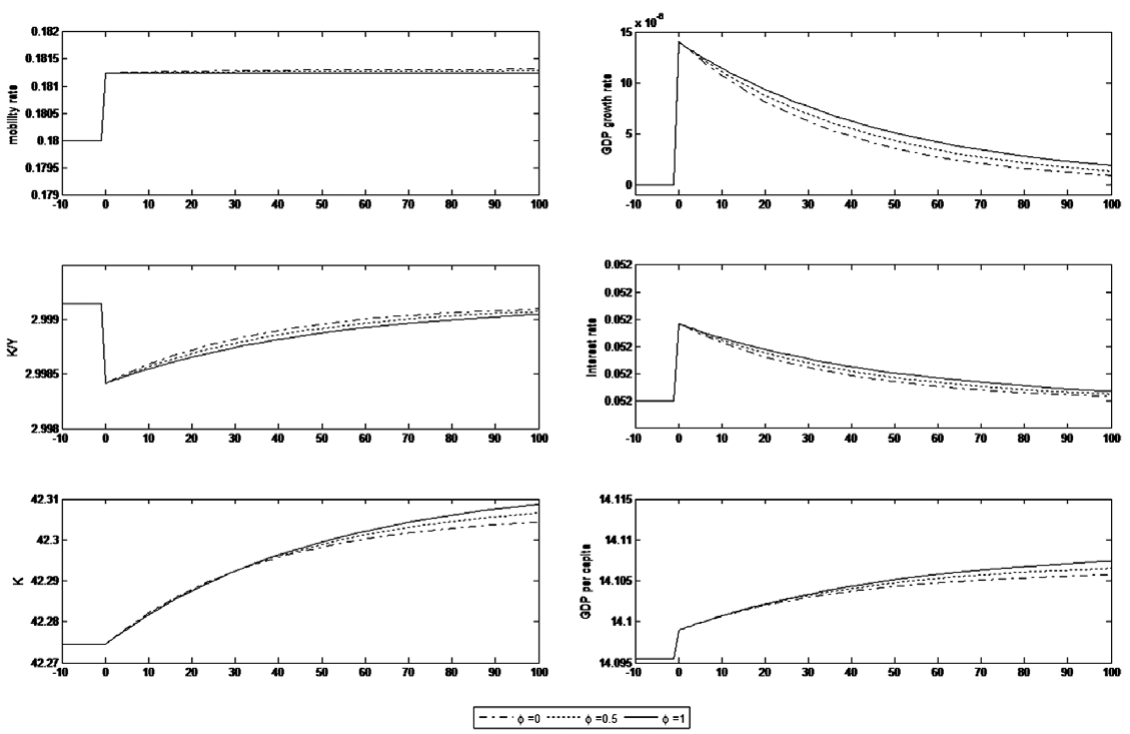

FIGURE 4. Transitional dynamics due to a permanent $20 \%$ reduction in the labor mobility cost when the elasticity of substitution is 0.1 .

Note that this implies that the time path of labor mobility is the opposite of the one obtained in Figure 2. Interestingly, these differences in the transitional dynamics of labor mobility do not cause qualitative differences in the transitional dynamics of the other economic variables, as follows from the comparison between Figures 2 and 3. This happens because labor mobility affects the other economic variables only by changing the TFP and the effects of labor mobility on the TFP depend on the elasticity of substitution: TFP increases with labor mobility if and only if $\sigma>0$, as follows from (25). In Figure 2, workers are complements $(\sigma<0)$ and labor mobility is lower when $\phi<1$. As $\sigma<0$, the lower labor mobility causes a larger TFP and a larger GDP. In contrast, in Figure 3, workers are substitutes $(\sigma>0)$ and labor mobility is larger when $\phi<1$. However, as $\sigma>0$, this higher labor mobility causes a larger TFP and a larger GDP. This explains why the time paths of capital, interest rate, and GDP are qualitatively the same in Figures 2 and 3.

Second, the speed of convergence is higher when workers are highly substitutable. ${ }^{25}$ The speed of convergence is $4.4 \%$ when $\phi=0$ and $3.1 \%$ when $\phi=0.5$. This higher speed of convergence when the elasticity of substitution is large is a consequence of a faster change in labor mobility as capital accumulates. Obviously, the faster change in labor mobility causes larger differences in GDP growth between the economy with constant labor mobility $(\phi=1)$ and that with nonconstant labor mobility $(\phi<1)$.

In Figures 4 and 5, we study the effects of a permanent shock in labor mobility costs, assuming that the economy is initially in a steady state. We analyze the shock of a $20 \%$ reduction in mobility costs, which implies a drop of mobility 

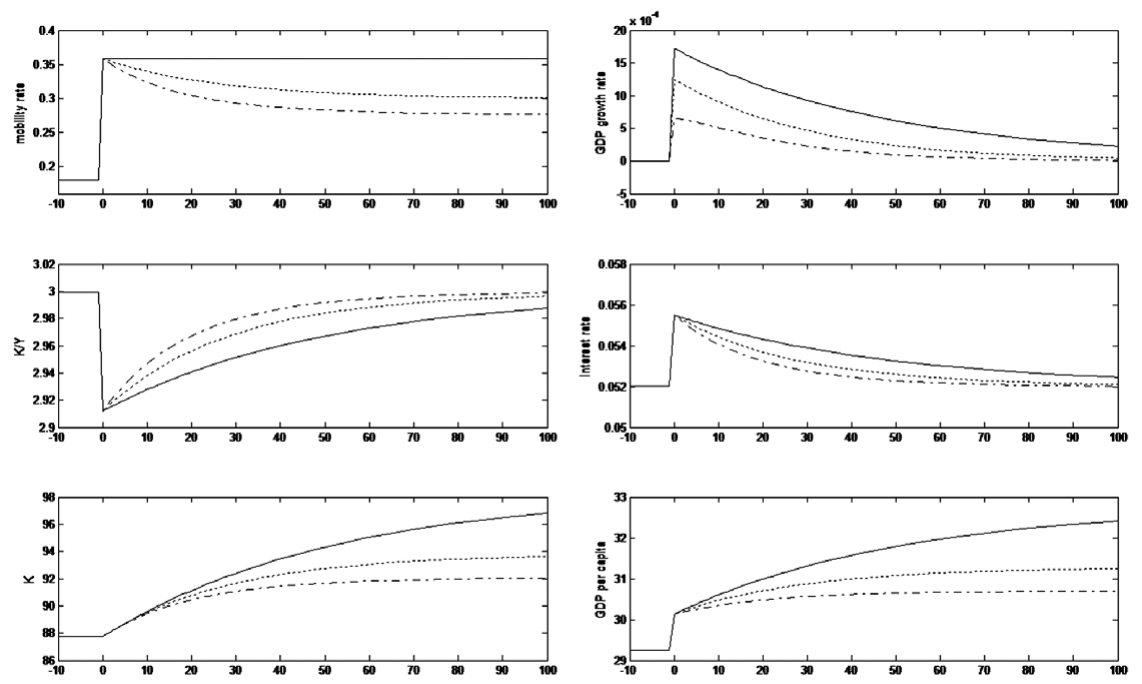

$-\cdot \cdot \bullet \cdot 0=0 \cdots \cdots \cdot \bullet=0.5-\varphi=1$

FIGURE 5. Transitional dynamics due to a permanent $20 \%$ reduction in the labor mobility cost when the elasticity of substitution is 10 .

costs from $50 \%$ to $40 \%$ of annual average income. A reduction in these costs initially increases labor mobility and TFP. As a result, the interest rate initially grows, implying an increase in the stock of capital during the transition. Because capital increases and TFP has jumped, the GDP growth rate initially increases. Decreasing returns to capital imply that both the interest rate and the GDP growth rate decrease as capital increases during the transition. In the long run, the ratio of capital to GDP, the interest rate, and the GDP growth rate converge toward the same steady state values, whereas the levels of labor mobility, capital stock, and GDP converge to higher values. Note that the long-run increase in GDP is a consequence of the rise in both the stock of capital and the TFP level.

There are two differences between Figures 4 and 5. First, in Figure 4 the elasticity of substitution is small. After the initial jump in labor mobility, capital increases and the relative productivity of poached workers decreases. Because workers are highly complementary, firms increase the number of poached workers to compensate for their lower productivity and, thus, labor mobility increases during the transition, although quantitatively by an insignificant amount. Instead, in Figure 5 the elasticity of substitution is large. Then, as the different types of worker are highly substitutable, firms decrease the number of poached workers and thus labor mobility decreases during the transition. Therefore, the same shock causes opposite transitional dynamics depending on the value of the elasticity of substitution. Second, from the comparison between these two figures, we conclude that the effects of a reduction in labor mobility costs are much greater when workers are highly substitutable. In this case, firms are more likely to replace 
retained workers with poached workers, thereby causing a greater increase in the long-run level of GDP. In our numerical example, the increase in GDP due to a $20 \%$ decrease in the mobility costs is by up to $12 \%$ when $\sigma=0.9$ and only $0.09 \%$ when $\sigma=-9$. Therefore, we conclude that labor mobility costs, by causing labor misallocation, are a more relevant source of cross-country per capita GDP differences when the different types of worker are highly substitutable.

\section{FURTHER INSIGHTS ON MOBILITY COSTS}

In this section we examine labor mobility costs in greater depth by analyzing labor income taxes and labor search costs. We show that differences in either taxes or search costs can boost or even be the cause of different labor mobilities across countries. Thus, we show that even in the presence of small differences in mobility costs, different labor income taxes or labor search costs can explain large cross-country differences in labor misallocation and growth.

\subsection{Labor Income Taxes}

The nonarbitrage condition in the labor market implies that poached workers must be compensated for both mobility costs and the net wage they would earn if they had not moved. Therefore,

$$
(1-\tau) w_{i}^{j}=(1-\tau) w_{j}^{j}+n,
$$

where $\tau \in(0,1)$ is the labor income tax rate and $n$ accounts for the labor mobility cost. This equation can be rewritten as $w_{i}^{j}=w_{j}^{j}+\hat{m}$, where $\widehat{m}=\frac{n}{1-\tau}$ is the compensation of the labor mobility cost paid by the firm. Therefore, $\widehat{m}$ measures the distortion introduced by labor mobility costs. Note that this distortion is increasing in the labor income tax rate. Therefore, taxes indirectly affect TFP through labor mobility. ${ }^{26}$

Assume also that government revenues are returned to consumers as a lumpsum transfer, so that there is no wealth effect. Thus, the only distortion due to taxes is via labor mobility costs. This conclusion and the analysis in this paper imply that those countries with a lower tax rate are also those countries with higher labor mobility and higher growth rates. This theoretical conclusion is supported by empirical evidence. The correlation between total tax wedge and labor mobility in the period 1994-2008 is clearly negative and significant, with a value of -0.68 . Figure 6 shows that countries with low labor taxes such as the United States or the United Kingdom have high labor mobility, whereas countries with high labor taxes such as Italy, Belgium, and France have low mobility.

\subsection{Labor Search Costs}

We introduce labor search into our economy. Contrary to the typical search models, we have neither unemployment nor separation rates (firms that close down). 


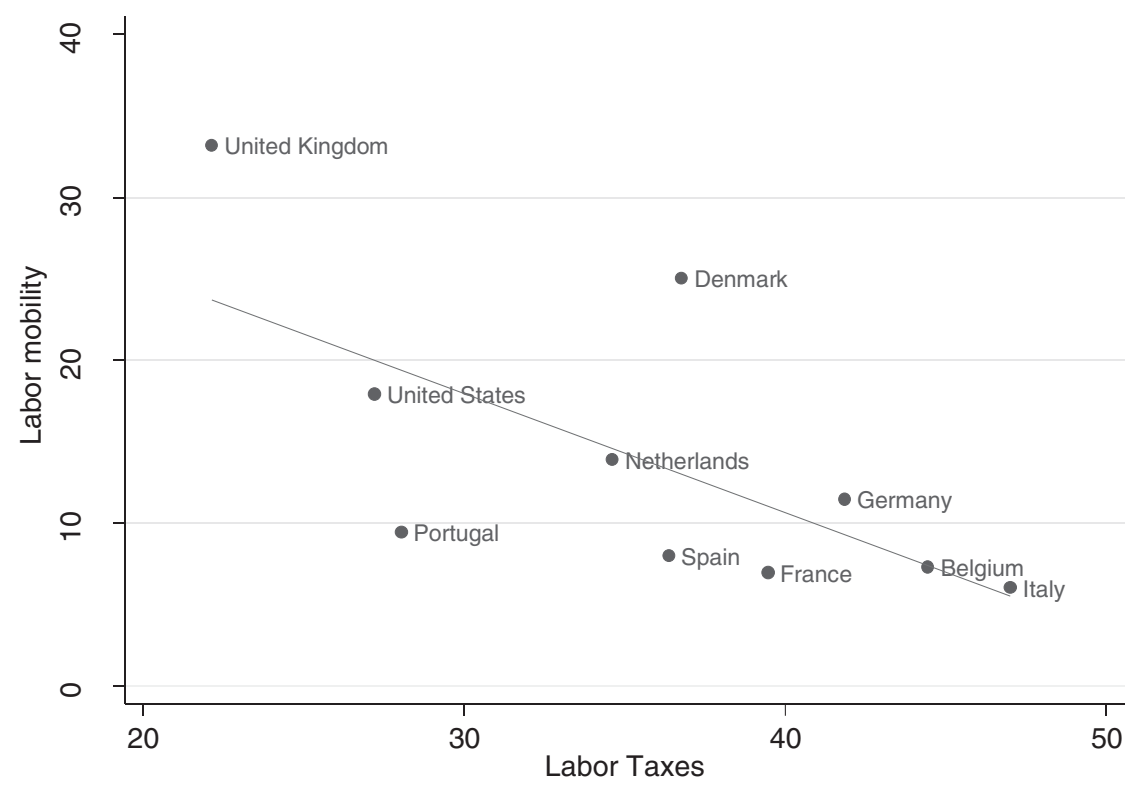

FIGURE 6. Labor taxes and labor mobility. Data on labor mobility from Jolivet et al. (2006) and total tax wedge from OECD year 1997 (average rate in \% based on two-earner married couple with two children, one earner at $100 \%$ of average earnings and the other at $33 \%$ ).

Instead, we have on-the-job-search: individuals who work in a firm and who are actively searching for another job. As usual, we assume that this search is costless for workers. In line with the previous sections, we assume that there are neither mobility costs nor search costs for hiring workers from the same sector. In this environment, a firm in sector $i$ opens a vacancy $V_{i}^{j}$ when it wants to poach a worker from sector $j$. This vacancy has an associated cost, $\kappa_{i}^{j}$, and a probability of being filled, $\pi^{j}$. This means that the number of poached workers will be a fraction $\pi^{j}$ of the posted vacancies, $\lambda_{i}^{j}=\pi^{j} V_{i}^{j}$, and that the cost of a poached worker is $\kappa_{i}^{j} / \pi^{j}+w_{i}^{j}$. Assuming that the vacancy costs are proportional to the hiring wage, $\kappa_{i}^{j}=s_{i}^{j} w_{i}^{j}$, where $s_{i}^{j}$ is a constant, and that mobility costs other than vacancy costs are a proportion $d$ of the wage, and given that perfect competition in the labor market implies that $w_{i}^{j}=(1+d) w_{j}^{j}$, we obtain that the total cost of hiring a poached worker is $\widehat{m} w_{j}^{j}$, where

$$
\widehat{m}=(1+d)\left(1+\frac{s_{i}^{j}}{\pi^{j}}\right) .
$$

As usual in the labor search literature, the probability of filling a vacancy $\pi^{j}$ decreases with labor market tightness. ${ }^{27}$ This implies that a higher labor market 
tightness results in a higher effective vacancy cost and, as follows from the expression of $\widehat{m}$, this causes an increase in the total cost of hiring a worker. On one hand, vacancy costs increase labor mobility costs $d$ and, thus, indirectly affect TFP growth. On the other hand, because vacancy costs are a type of mobility cost, even in the absence of these, $d=0$, vacancy costs increase the hiring costs, causing misallocation of labor and, thus, directly affecting TFP growth. We conclude from this result that countries with high labor market tightness will be more strongly affected by mobility costs than countries with low market tightness and, similarly, that mobility costs will matter more in periods of high labor market tightness (economic booms) and less in recessions.

\section{CONCLUDING REMARKS}

We have considered labor mobility as one of the factors that account for differences in TFP across countries. In so doing, we have introduced learning-by-hiring into a model of learning-by-doing, so that although firms in a sector may have free and instant access to the knowledge developed within their own sector, they can only learn from other sectors by hiring external workers (learning-by-hiring). Hence, hiring decisions and, thus, worker allocation affect knowledge exploitation and, therefore, TFP.

We obtain a positive relationship between growth and labor mobility, which is consistent with empirical evidence. Moreover, we find that the number of worker types affects growth, and that these effects depend on the elasticity of substitution among the types of workers. Our results reveal that, apart from the traditional decreasing returns to capital, labor mobility might act as a force driving the transition. We show that changes in mobility costs matter the most when the elasticity of substitution among the types of worker is high. Therefore, the impact of different mobility costs is especially significant when different types of workers have small complementarities. As a consequence, policies that reduce mobility costs are more effective when workers are highly substitutable. Finally, we show that differences in either labor income taxes or labor search costs can explain differences in labor mobility among countries and, therefore, in their growth rates.

Labor market regulations and the public system of unemployment benefits affect labor mobility and, thus, indirectly affect GDP. The aim of future research is to study if the different labor market regulations account for part of the differences in both labor mobility and GDP levels.

\section{NOTES}

1. See Banerjee and Moll (2010) and Restuccia and Rogerson (2013) for a comprehensive review of other recent papers that show that the misallocation of resources might explain large cross-country TFP differences.

2. The notion that mobility of individuals matters for diffusion of knowledge has been used in models with international diffusion of knowledge through cross-border flows of people [see Lucas 
(1993) and Andersen and Dalgaard (2011)]. The assumption is in line with the finding in Machin et al. (2012) that labor mobility is positively related to individuals' level of education.

3. In the labor literature, Lee and Wolpin (2006), when studying the growth of the service sector, also assume that workers are heterogeneous and not perfect substitutes. Our paper differs from theirs in two main aspects: first, their source of labor heterogeneity comes from education and work experience accumulated in each sector-occupation, whereas our labor heterogeneity comes from recent sector-specific learning-by-doing, so that in the steady state years of experience do not increase labor productivity in our setup. Second, we highlight the importance of the elasticity of substitution among the different types of worker.

4. Lee and Wolpin (2006) show that mobility costs are substantial when mobility is across sectors in the United States (between 50\% and 75\% of average annual earnings), whereas they are small when mobility is across firms of the same sector. An analysis of the importance of mobility costs across sectors can be found in Steger (2007).

5. Data on labor mobility also include information on Ireland. We exclude it from the analysis, however, because its high growth rate during the studied period is explained by exceptional circumstances such as a large attraction of foreign direct investment.

6. We measure labor mobility by computing the odds of an individual changing jobs. These are computed as the percentage of individuals who changed job in a three-year spell divided by the percentage of individuals who did not change job during this period. We draw this measure multiplied by 100 . We use the same measure for labor mobility in both the theoretical model and its calibration.

7. Several papers report the importance of the exchange of knowledge as an engine of innovation and growth [see Audretsch and Feldman (1996) and Almeida and Kogut (1999)]. Many of them emphasize the importance of intersectoral rather than intrasectoral knowledge spillovers [see Glaeser et al. (1992) and Hanson (2001)].

8. A similar intuition explains the results in Hsieh and Klenow (2009), though they consider the elasticity of substitution between sector outputs. Similar results are also obtained by Jones (2011), who argues that problems along a production chain can decrease output under complementarity. But, whereas he considers complementarity in intermediate inputs (elasticity of substitution smaller than 1), we consider all possible degrees of substitution/complementarity in the labor input.

9. Blanchflower and Oswald (2013) find that a high homeownership rate leads to future rises in unemployment. They identify three mechanisms through which this relationship might operate: lower levels of labor mobility, greater commuting times, and fewer new businesses in the region with higher homeownership. Our paper provides an explanation for the mechanism relating labor mobility, homeownership (which increases mobility costs), and economic performance.

10. Similarly, Restuccia and Rogerson (2008) find that setting taxes or subsidies to establishmentlevel labor affects TFP through a reallocation of resources among heterogeneous firms.

11. Lagos (2006) shows in a search model that the level of TFP depends on all the characteristics of the labor market summarized by the job-creation and job-destruction decisions. In particular, he centers on how labor market policies can affect the aggregate TFP by affecting the pool of active firms. In our paper, in contrast, search affects TFP by reallocating labor across sectors.

12. Time subscripts are suppressed to enhance readibility.

13. Arrow (1962) assumes that learning in sector $i$ is a function of the investment made in the last period in that sector. As workers do not move across sectors, this assumption implies that the accumulated learning in a given sector coincides with the stock of capital. To make comparisons with the original paper by Arrow, we must assume that (i) firms are interested in the knowledge a worker has learned in the last period and (ii) learning is accumulated from the stock of capital. These two assumptions imply that, even with mobility across sectors, the knowledge of workers coincides with the average stock of capital in the last sector in which they have been employed. Thus, these two assumptions allow direct comparison with Arrow's original paper.

14. Thoenig and Verdier (2010) also consider knowledge as embodied in workers. However, they study knowledge management as a strategic choice of the firm. 
15. Note that for a firm in sector $i$ the potential retained workers are not only the workers of this firm but all the workers in sector $i$, because there are no mobility costs for them. Given that there is a continuum of firms in each sector, the hiring decisions of a firm in sector $i$ do not affect the supply of labor with knowledge type $i$.

16. Mobility costs are assumed to be proportional to the wage, as they are generally related to reallocation expenses or time opportunity costs - for example, training costs, hiring costs, and search costs.

17. Note that these mobility costs would be identical to a tax on the cost of labor of the poached workers, as long as government revenues were spent on nonproductive goods.

18. The supply of workers of type $i$ is $N_{i}=\eta+\int_{0}^{S} \lambda_{i}^{j} d j=\eta+S \lambda^{j}$ and the demand for these workers is $N_{i}=\eta+\int_{0}^{S} \lambda_{j}^{i} d j=\eta+S \lambda^{i}$. In a symmetric equilibrium, (14) implies that $\lambda^{i}=\lambda^{j}$ for all $i$ and $j$.

19. A referee has suggested another potentially interesting case: $\xi=1, q>0$, and $\phi<1$. In this case, convergence is driven only by labor mobility. When $\sigma>0$, as capital accumulates, labor mobility decreases until it converges to zero in the long run. As a consequence, the long-run equilibrium exhibits sustained growth and the long-run growth rate is equal to the one obtained in Arrow (1962). In contrast, when $\sigma<0$, as capital accumulates, labor mobility increases and, as a consequence, the growth rate decreases. The equilibrium converges to a steady state without sustained growth. As in the neoclassical growth model, the growth rate decreases as capital accumulates. Thus, the transitional dynamics driven by labor mobility is similar to that obtained in the neoclassical growth model, where convergence is driven by the diminishing returns to capital.

20. Note that even with zero mobility costs, there exists a finite optimal level of labor mobility [defined in (30)] because firms always want to retain some of their workers.

21. Note that the value of the parameters $S$ and $q$ cannot be disentangled and we can only fix $S q^{1 /(1-\sigma)}$.

22. Zero mobility costs imply a mobility rate close to $27 \%$. Figure 1 shows small differences in GDP growth between the case of zero mobility costs and the U.S. level. This analysis suggests that there is little misallocation in the United States due to mobility costs.

23. If $\xi<1$ and $\phi \in(1,1 / \xi$, ) then the productivity of poached workers relative to the productivity of retained workers increases as capital accumulates. Using (23) and (25), it can be shown that in this case total factor productivity rises with the capital stock because of labor mobility. As a consequence, the marginal productivity of capital exhibits a nonmonotonic relationship with the capital stock that may cause the existence of multiple steady states and complex equilibrium dynamics.

24. In the long run, investment is set to replace the existing stock of capital, because there is no capital accumulation. In a growing economy, in each period there is capital growth of about $2 \%$. We have assumed that this amount of resources is devoted to consumption expenditures. This means that in this economy consumption expenditures are $70 \%$ of GDP plus $2 \%$ of capital growth. Given that capital is three times GDP, this amounts to $76 \%$ of GDP.

25. This is related to the results in Ortigueira and Santos (1997), who study the speed of convergence in endogenous growth models with two sectors. They show that with the introduction of adjustment costs, the speed of convergence is reduced strongly. The level of complementarity of workers can be seen as a production constraint. Therefore, our results are consistent with those in Ortigueira and Santos (1997).

26. Only if mobility costs were proportional to net wage would taxes not affect these costs.

27. Labor market tightness is defined as the ratio between the number of vacancies for workers of type $j$ and the number of workers of type $j$ that are searching for a job (on-the-job-search).

\section{REFERENCES}

Almeida, Paul and Bruce Kogut (1999) Localization of knowledge and the mobility of engineers in regional networks. Management Science 45, 905-917. 
Andersen, Thomas Barnebeck and Carl-Johan Dalgaard (2011) Flows of people, flows of ideas, and the inequality of nations. Journal of Economic Growth 16, 1-32.

Arrow, Kenneth J. (1962) The economic implications of learning by doing. Review of Economic Studies 29, 155-173.

Audretsch, David B. and Maryann P. Feldman (1996) R\&D spillovers and the geography of innovation and production. American Economic Review 86, 630-640.

Banerjee, Abhijit V. and Benjamin Moll (2010) Why does misallocation persist? American Economic Journal: Macroeconomics 2, 189-206.

Barro, Robert J. (1990) Government spending in a simple model of endogenous growth. Journal of Political Economy 98, 103-125.

Barseghyan, Levon and Ricardo DiCecio (2011) Entry costs, industry structure, and cross-country income and TFP differences. Journal of Economic Theory 146, 1828-1851.

Blanchflower, David G. and Andrew J. Oswald (2013) Does High Home-Ownership Impair the Labor Market? Working paper 13-3, Peterson Institute for International Economics.

Dixit, Avinash and Rafael Rob (1994) Switching costs and sectoral adjustments in general equilibrium with uninsured risk. Journal of Economic Theory 62, 48-69.

Fernald, John and Brent Neiman (2011) Growth accounting with misallocation: Or, doing less with more in Singapore. American Economic Journal: Macroeconomics 3, 29-74.

Glaeser, Edward L., Hedi D. Kallal, Jose A. Scheinkman, and Andrei Shleifer (1992) Growth in cities. Journal of Political Economy 100, 1126-1152.

Hall, Robert E. and Charles I. Jones (1999) Why do some countries produce so much more output per worker than others? Quarterly Journal of Economics 114, 83-116.

Hanson, Gordon H. (2001) Scale economies and the geographic concentration of industry. Journal of Economic Geography 1, 255-276.

Heston, Alan, Robert Summers, and Bettina Aten (2012) Penn World Table Version 7.1, Center for International Comparisons of Production, Income and Prices at the University of Pennsylvania.

Hsieh, Chang-Tai and Peter J. Klenow (2009) Misallocation and manufacturing TFP in China and India. Quarterly Journal of Economics 124, 1403-1448.

Hsieh, Chang-Tai and Peter J. Klenow (2010) Development accounting. American Economic Journal: Macroeconomics 2, 207-223.

Jolivet, Grégory, Fabien Postel-Vinay, and Jean-Marc Robin (2006) The empirical content of the job search model: Labor mobility and wage distributions in Europe and the US. European Economic Review 50, 877-907.

Jones, Charles I. (2011) Intermediate goods and weak links in the theory of economic development. American Economic Journal: Macroeconomics 3, 1-18.

Jovanovic, Bojan and Robert Moffitt (1990) An estimate of a sectoral model of labor mobility. Journal of Political Economy 98, 827-852.

Klenow, Peter J. and Andrés Rodriguez-Clare (1997) Economic growth: A review essay. Journal of Monetary Economics 40, 597-617.

Lagos, Ricardo (2006) A model of TFP. Review of Economic Studies 73, 983-1007.

Lee, Donghoon and Kenneth I. Wolpin (2006) Intersectoral labor mobility and the growth of the service sector. Econometrica 74, 1-46.

Lucas, Robert E. (1993) Making a miracle. Econometrica 61, 251-272.

Machin, Stephen, Kjell G. Salvanes, and Panu Pelkonen (2012) Education and mobility. Journal of the European Economic Association 10, 417-450.

McGrattan, Ellen R. and James A. Schmitz, Jr. (1999) Explaining cross-country income differences. In John B. Taylor and Michael Woodford (eds.), Handbook of Macroeconomics, Vol. 1, Part A, pp. 669-737. Amsterdam: North-Holland.

Moscarini, Giuseppe (2001) Excess worker reallocation. Review of Economic Studies 68, 593-612.

Moscoso Boedo, Hernan J. and Toshihiko Mukoyama (2012) Evaluating the effects of entry regulations and firing costs on international income differences. Journal of Economic Growth 17, 143-170.

OECD.Stat, Data on Total Labor Tax Wedge for year 1997, http://www.oecd.org. Accessed 20 January 2013. 
Ortigueira, Salvador and Manuel Santos (1997) On the speed of convergence in endogenous growth models. American Economic Review 87, 383-399.

Parente, Stephen L. and Edward C. Prescott (2004) A unified theory of the evolution of international income levels. Federal Reserve Bank of Minneapolis Staff Report 333.

Poschke, Markus (2009) Employment protection, firm selection, and growth. Journal of Monetary Economics 56, 1074-1085.

Prescott, Edward C. (1998) Needed: A theory of total factor productivity. International Economic Review 39, 525-551.

Prescott, Edward C. (2004) Why do Americans work so much more than Europeans? Federal Reserve Bank of Minneapolis Quarterly Review 28, 2-13.

Rebelo, Sergio (1991) Long-run policy analysis and long-run growth. Journal of Political Economy 99, 500-521.

Restuccia, Diego and Richard Rogerson (2008) Policy distortions and aggregate productivity with heterogeneous establishments. Review of Economic Dynamics 11, 707-720.

Restuccia, Diego and Richard Rogerson (2013) Misallocation and productivity. Review of Economic Dynamics 16, 1-10.

Rogerson, Richard (1987) An equilibrium model of sectoral reallocation. Journal of Political Economy 95, 824-834.

Romer, Paul M. (1986) Increasing returns and long run growth. Journal of Political Economy 94, 1002-1037.

Romer, Paul M. (1990) Endogenous technological change. Journal of Political Economy 98, S71-S102.

Steger, Thomas M. (2007) Flexibility, sectoral hysteresis, and downturns. Macroeconomic Dynamics $11,128-148$.

Thoenig, Mathias and Thierry Verdier (2010) A macroeconomic perspective of knowledge management. Journal of Economic Growth 15, 33-63.

\section{APPENDIX A: PROOF OF PROPOSITION 1}

When $\sigma<1$, (23) implies that (17) and (18) hold simultaneously in equality. When $\sigma=1$, the expression for $x$ is not defined in (23). In this case, if $k>\widetilde{k}$ then only (18) holds with equality, which implies that $\eta=0$. If $k<\widetilde{k}$ then only (17) holds with equality, which implies that $\lambda=0$. Finally, when $k=\widetilde{k}$, then (17) and (18) hold with equality for any value of $x$.

\section{APPENDIX B: PROOF OF PROPOSITION 3}

From equations (25) and (30) we have

$$
\frac{d h}{d m}=\frac{\alpha h x(1-m)}{(1-\sigma)(1+m x)(1+x) m}<0,
$$

which is negative because $m>1$ and $\sigma<1$. Therefore, $\partial g / \partial m<0$. 
From the same two equations, we obtain

$$
\frac{\partial h(x)}{\partial S}=\alpha h\left[\frac{m-\sigma+(1-\sigma) m x}{\sigma(1+m x)(1+x)}\right]\left(\frac{x}{S}\right) .
$$

Because $m>1$ and $\sigma<1$, this derivative is positive when $\sigma>0$ and negative when $\sigma<0$. Therefore, result (b) follows.

\section{APPENDIX C: PROOF OF PROPOSITION 4}

We first show existence and uniqueness of the steady state. To this end, we combine (28) and (23) when $\dot{c}=0$ to obtain

$$
h(x)^{z}=b^{z} x
$$

where

$$
b=\left(\frac{\delta+\rho}{1-\alpha}\right)\left(\frac{m}{q S^{1-\sigma}}\right)^{\frac{\alpha(1-\xi)}{\xi \sigma(\phi-1)}}
$$

and

$$
z=\frac{\xi \sigma(\phi-1)}{\alpha(1-\xi)(1-\sigma)} .
$$

The roots of this equation are the steady state values of labor mobility. Note that

$$
\frac{\partial h(x)^{z}}{\partial x}=\alpha z h(x)^{z}\left[\frac{(m-\sigma)+m x(1-\sigma)}{\sigma(1+x)(1+m x)}\right] .
$$

It follows that $\partial h(x)^{z} / \partial x>(<) 0$ if and only if $\phi>(<) 1$. Given that $h(0)=1>0$ and $h(\infty)^{z} \rightarrow 0$ if $\phi<1$, there is a unique steady state when $\phi<1$. If $\phi>1$, then $h(\infty)^{z} \rightarrow \infty$ and there is the possibility of multiple steady states. Finally, if $\phi=1$, then labor mobility is constant and there is a unique steady state.

Next, we proceed to show saddlepath stability when $\phi \leq 1$. Evaluating at the steady state, we have $\partial \dot{c} / \partial c=0, \partial \dot{k} / \partial c=-1$, and

$$
\begin{aligned}
\frac{\partial \dot{c}}{\partial k} & =c \frac{(1-\alpha) k^{\alpha(\xi-1)}}{\theta}\left[h^{\prime}(x) \frac{\partial x}{\partial k}+\alpha(\xi-1) \frac{h(x)}{k}\right] \\
& =c \frac{(1-\alpha) \alpha h(x) k^{\alpha(\xi-1)-1}}{\theta}\left\{x\left[\frac{(m-\sigma)+m x(1-\sigma)}{(1+x)(1+m x)}\right]\left[\frac{\xi(\phi-1)}{1-\sigma}\right]+(\xi-1)\right\} .
\end{aligned}
$$

Note that $\partial \dot{c} / \partial k<0$ if $\phi \leq 1$. This implies that the equilibrium is saddle path stable when $\phi \leq 1$. 